\title{
Operating efficiency of BelAZ-7540 dump trucks under conditions of North
}

\author{
Ishkov Aleksander M. \\ Mining Machinery Department \\ North-Eastern Federal University n.a. M.K. Ammosov \\ Yakutsk, Russia \\ gormashygu@mail.ru
}

\author{
Makhno Dmitriy E. \\ Mining Machinery and Electromechanical Systems \\ Department \\ Irkutsk National Research Technical University \\ Irkutsk, Russia \\ fai@istu.edu
}

\author{
Bochkarev Yuriy S. \\ Mining Machinery Department \\ North-Eastern Federal University n.a. M.K. Ammosov \\ Yakutsk, Russia \\ ys.bochkarev@s-vfu.ru
}

\begin{abstract}
Development of mineral fields requires use of various machines. In the North, truck operation goes hand in hand with failures. Statistical analysis identified the effect of ambient temperatures on operating efficiency of BelAZ-7540 dump trucks. It was established that the number of failures increases two or three times when the ambient temperature decreases. The article identified the systems limiting operating performance of mining dump trucks. Maintenance and repair services can increase operating efficiency of trucks. Cosinoranalysis-based method identified latent failure intervals. Analysis of truck operation conditions determined the effect of operating intensity on the operating efficiency of trucks in the washing season. It was also identified that maintenance and repair intervals determined by the plant do not take into account operating conditions (seasonal prevalence). Therefore, maintenance services should depend on the operating time of truck components.
\end{abstract}

Keywords - BelAZ, failure, temperatures, cosinor-analysis, repair, interval.

\section{INTRODUCTION}

The XXI century opened a new stage in the year-round development of placer deposits in the North. More than $75 \%$ of mineral deposits are located in the Urals, Siberia and the Far East [1].

Intensification of deposit development in the North requires wide use of mining and motor transport machines. One of the most labor-consuming and expensive open mining processes is rock mass transportation. About half of workers are involved in that process. Transport costs are over half of the total costs for mining. The most common type of mining transport is motor transport. It transports $60 \%$ of rock mass in Russia, and $85 \%$ - in other countries. Wide use of motor transport is due to its high maneuverability and insignificant initial investment. Dump trucks can be used for not longdistance transportation, rugged relief and deep pits.

More than $70 \%$ of open-pit mining operations take place in the Far North and other northern regions of Russia with severe climatic conditions (machines are operated at $-60^{\circ} \mathrm{C}$ ). Poor truck maintenance might be also due to long distances from central Russian regions and high production costs because of high labor and transport costs.

Open-pit mining technology involves five stages: rock development for mining, rock excavation, transportation, concentration, and dumping. All the stages are closely connected and dependent on each other.

Transportation within the mining industry is carried out by motor vehicles. In Russia and CIS states, the share of mining motor transport is about $75 \%$. Motor transport will dominate at open mines for other 20-30 years due to the lack of alternatives [2].

Komatsu, Caterpillar, Liebherr, and BelAZ trucks are used at northern open mines. Belorussian Automobile Plant produces the most common trucks; for example, 14 industries of the Far East use BelAZ trucks with hydromechanical transmission [2].

BelAZ operating experience has been described by a number of researchers, but most of them study the operating efficiency of 110-220 ton payload capacity dump trucks [1-6]. Only some researches deal with 30-40 ton payload capacity dump trucks which are widely used at open mines of Yakutia from Nerungri to Oymyakon and Anabar.

The article aims at studying the operating efficiency of 3040 ton payload capacity dump trucks for the northern open-pit mines. The research object is BelAZ-7540 truck employed by JSC Almazy Anabara.

\section{RESULTS AND DISCUSSION}

The authors selected statistical data on the operating efficiency of ten BelAZ-7540A dump trucks which have been operated by JSC Almazy Anabara in Mayat for three years. The statistical data were taken from garage documents since they are new and classified by the systems in Table 1 [7]. 
TABLE I. DISTRIBUTION OF BELAZ - 7540 DUMP TRUCK FAILURES

\begin{tabular}{|l|c|c|c|}
\hline \multirow{2}{*}{ System } & \multicolumn{3}{|c|}{ Failures, number } \\
\cline { 2 - 4 } & $\begin{array}{c}\text { number } \\
\text { of } \\
\text { failures }\end{array}$ & $\begin{array}{c}\text { number of } \\
\text { failures at } \\
\text { negative } \\
\text { temperatures }\end{array}$ & $\begin{array}{c}\text { number of } \\
\text { failures at } \\
\text { positive } \\
\text { temperatures }\end{array}$ \\
\hline power unit & 679 & 433 & 246 \\
\hline engine unit & 622 & 436 & 186 \\
\hline drive axle & 380 & 191 & 189 \\
\hline wheels and tires & 373 & 213 & 160 \\
\hline brake system & 342 & 183 & 159 \\
\hline electrical equipment & 325 & 211 & 114 \\
\hline Transmission system & 253 & 161 & 92 \\
\hline cab, platform & 152 & 88 & 64 \\
\hline front axle & 84 & 42 & 42 \\
\hline Steering system & 74 & 30 & 44 \\
\hline dumping mechanism & 35 & 18 & 17 \\
\hline total & 3319 & 2006 & 1314 \\
\hline
\end{tabular}

Figure 1 shows that the failures of the drive axle, suspension system, wheels and tires, electrical equipment, transmission system, and braking system amount to $90 \%$ of all failures. Those systems limit dump truck performance.

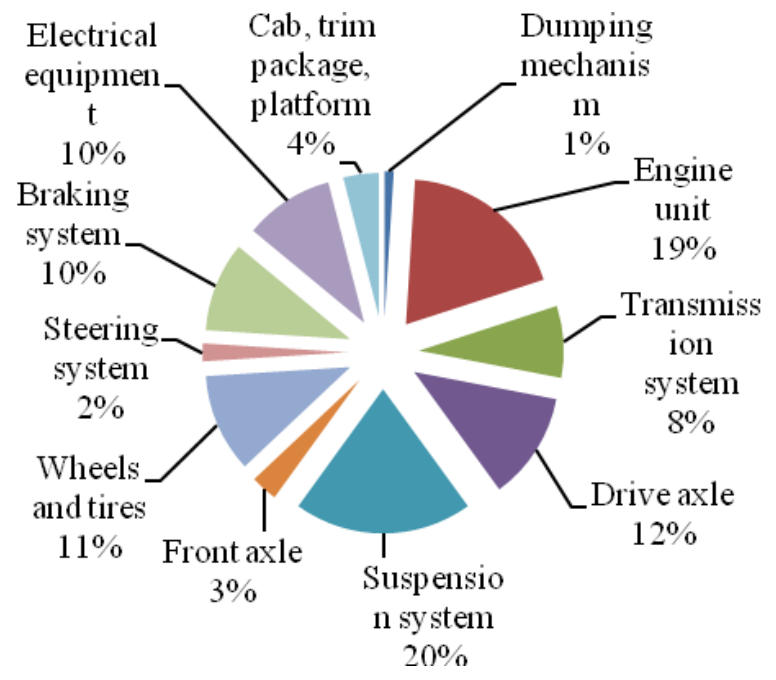

Fig. 1. Failures of BelAZ-7540 dump truck

Dumping mechanism - 1

Engine unit - 19

Transmission system -8

Drive axle - 12

Suspension system -20

Front axle -3

Wheels and tires -11

Steering system -2

Braking system -10

Electrical equipment - 10

Cab, trim package, platform - 4

Thorough analysis identified that the most frequently replacement wear part is a friction-type bearing (Fig. 1) which is a part of such components as hydro cylinders of the suspension system, a lifting mechanism of the platform, a steering system, and suspension rods. Wear of the frictiontype bearing causes a play in joints of those components.
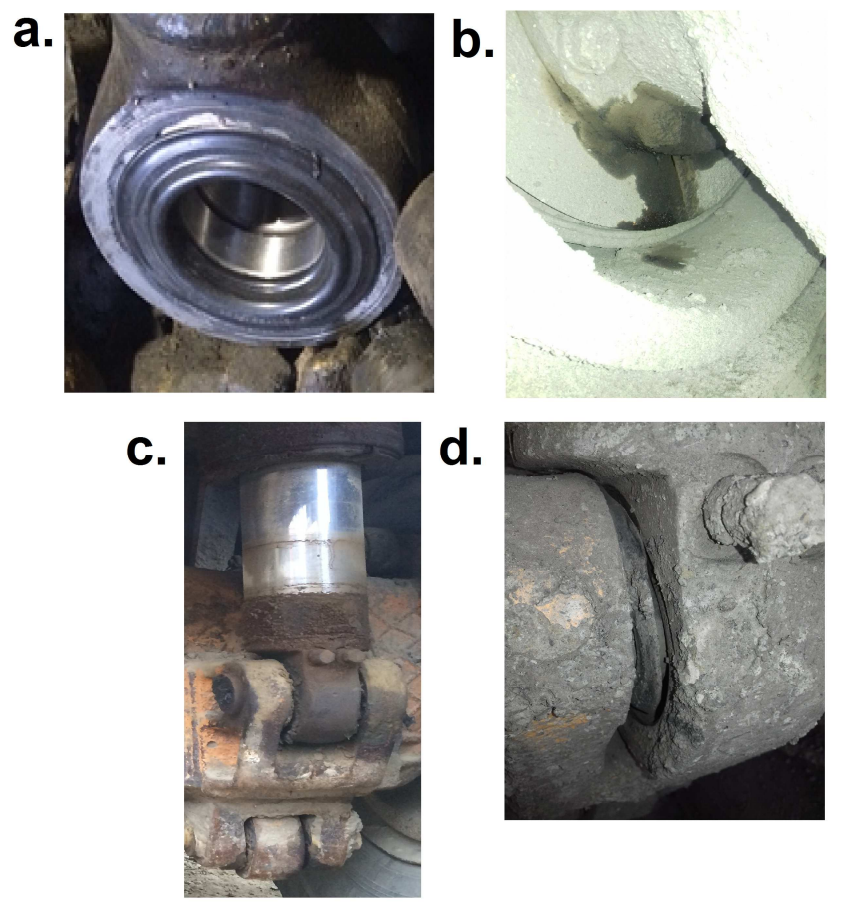

Fig. 2. a. - bearing rod front suspension, b. - oil leaks through the sealant drive axle, c. - rock dust on the cylinder, d. - misalignment of the bearing boot rear suspension

Analysis identified that the main failure factors are rock dust, humidity, and stresses. Boot failure also causes fast wear of the components which fail to prevent the entry of dust and dirt and lubricant leakage.

The most widespread failure is wear of various seals (Fig. $2, \mathrm{~b}, \mathrm{c}, \mathrm{d})$ resulting in leakage of lubricants and hydraulic liquids. The main causes of that failure are low temperatures, abrasive wear and combination of abrasive wear and mechanical damages, shifts and misalignment.

Figure 2 shows mean daily temperatures in Mayat (Fig.3).

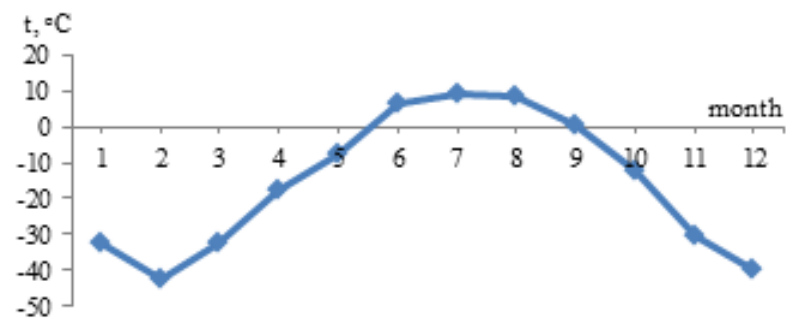

Fig. 3. Mean daily temperatures

As can be seen, the warm period lasts only four months: June, July, August, and September. The warmest month is July. The other months are cold. Extremely low temperatures are typical for February. 
Operating efficiency of dump trucks depends on various factors which determine operating parameters (temperature, humidity, wind velocity, industry efficiency, transportation distances, the relief, the type and quality of roads, the type of a loader, the type and characteristics of the load, conditions of a repair station, speed modes, the vehicle type and age).

Failure flow $\omega$ is an efficiency parameter for dump trucks which is determined as a relation of the mathematical prediction of the number of failures of the object for its short operating time to the operating time. It can be written in form:

$$
\omega=\frac{1}{T}
$$

$\mathrm{T}$ is a mean operating time.

Figure 4 shows calculation results for the failure flow by months.

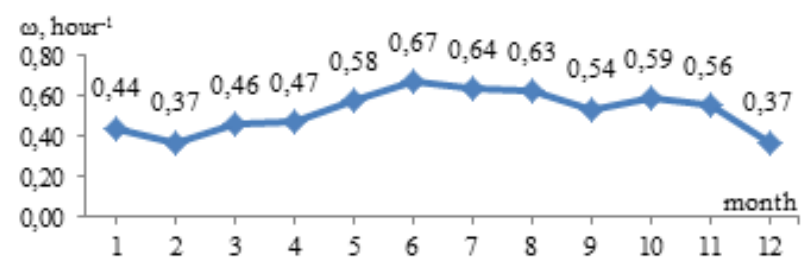

Fig. 4. Failure flow throughout the year

As can be seen that the failure flow increases by the beginning of the washing season, which is illustrative of the increase in mining operations. By the end of the year, the failure flow decreases due to the end of the washing season. It is typical for the northern placer deposits.

Dump trucks operate in cold climatic conditions. Therefore, the authors analyzed the level of impact of ambient temperatures on their operating efficiency. The results are presented in Figure 5.

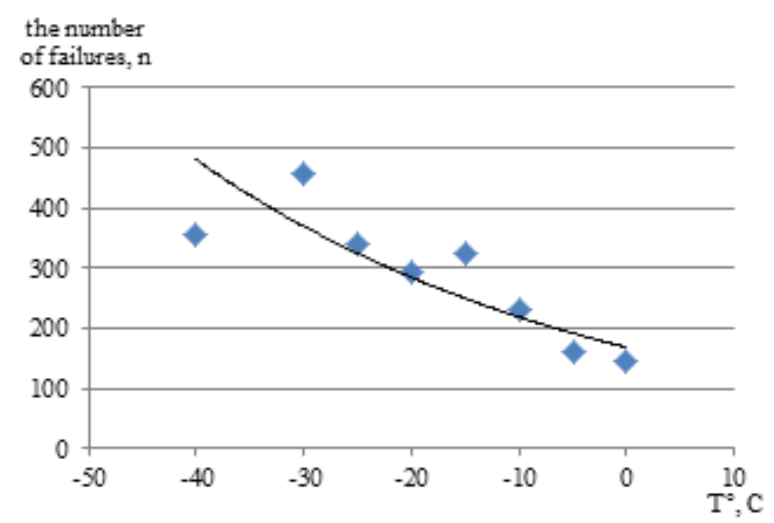

Fig. 5. Temperature dependence of failures

Figure 4 shows that the number of failures increases at $30^{\circ} \ldots 40^{\circ} \mathrm{C}$. It speaks for the dependence of the number of failures on the ambient temperature.

The statistical data say that climatic conditions (negative temperatures) influence the suspension system, power unit, drive axle, wheels and tires, transmission, electric equipment, braking system, cab, and platform. However, there is no direct impact of the negative temperatures on the front axle, steering system and tilting mechanism.

The analysis showed that the maintenance and repair (MR) system ensures high dump truck efficiency in the North. Therefore, MR intervals should be adjusted.

Preventive MR involves scheduled inspection, maintenance and protection of objects before break down or other problems occur. But due to average target dates of preventive MR measures, lives of components and parts can be reduced.

At present, scheduled MR is giving way to corrective MR which means that equipment is repaired after diagnostic monitoring. The drawback of that strategy is a forced outage of vehicles.

However it is impossible to abandon scheduled MR measures as far as a significant portion of vehicles might fail at once, which misbalances mining operations and creates a significant load on maintenance workers. Besides, consequences of some failures are eliminated on a scheduled basis which decreases idle time of vehicles. MR measures are also connected with production processes. Volumes of work are specified and spare parts and expendable materials are prepared in advance.

A strategic decision making algorithm for selecting MR methods is presented in Figure 6.

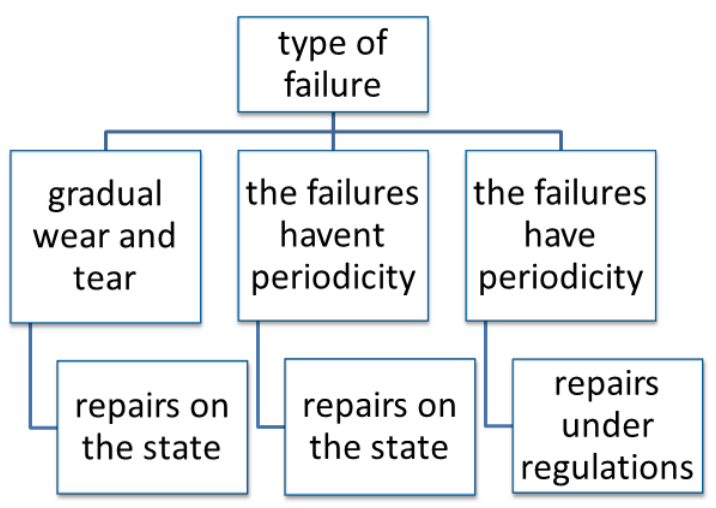

Fig. 6. Strategic decision making algorithm for selecting MR methods

Figure 5 shows that the MR strategy depends on the type of failures. The truck is a complex system. The processes in its components and mechanisms have a cyclic nature due to the cyclic nature of external factors. Predictions of changes in external factors can improve performance.

Thus, the dump truck can be presented as a mechanical system interacting with the environment which can be compared with physiological processes in live organisms which are studied using a cosinor method.

That method helps identify latent periodicity of different processes to establish latent relations of quantitative indicators 
and external factors as well as to predict those indicators for future periods.

The advantage of the method is that measurements can be both equidistant and not equidistant from each other, i.e. observations do not have to be continuous.

The cosinor method is used for processing time series data approximated by a cosine function. Input data is a pencil of chronograms, and output results are amplitude (A), and acrophase $(\varphi)$ - the moment of maximum vibrations. The points in Cartesian coordinates are two-dimensional normally distributed random values.

In order to determine the latent intervals of BelAZ-7540 truck failures depending on its operating time, the following model was used:

$$
\begin{gathered}
\mathrm{U}(\mathrm{t})=\mathrm{Acos}\left(\omega_{0} \mathrm{t}-\varphi\right)+\mathbf{h}+\mathrm{pt}= \\
=\mathrm{x} \cos \left(\omega_{\mathrm{o}} \mathrm{t}\right)+\mathrm{y} \sin \left(\omega_{\mathrm{o}} \mathrm{t}\right)+\mathbf{h}+\mathbf{p t} .
\end{gathered}
$$

A is the amplitude, $\varphi$ is the acrophase, $\mathrm{h}$ is the mean number of failures, $p$ is the linear coefficient of the increase in the number of failures to be assessed, $\omega_{0}$-is the angular frequency equal to $2 \frac{\pi}{\mathbf{T}}$ where $\mathrm{T}$ is the operating time, $\mathrm{t}-$ the moment of time, $U(t)$ - the number of failures.

Transforming (2), the authors obtain a system of four equations with four variables $-\mathrm{x}, \mathrm{y}, \mathrm{h}, \mathrm{p}$ :

Thus, there is a quartic:

$$
\mathbf{X}\left(\omega_{0} t_{\mathrm{i}}\right)^{2 n}
$$

Solving (5), there are $\mathrm{x}, \mathrm{y}, \mathrm{h}, \mathrm{p}$.

Then the authors determine amplitude A:

$$
A=\sqrt{x^{2}+y^{2}}
$$

Then acrophase $\varphi$ is determined given that:

$$
\left\{\begin{array}{c}
\varphi=\operatorname{arctg}\left(\frac{y}{x}\right), \text { если } x \geq 0, \\
\varphi=\operatorname{arctg}\left(\frac{y}{x}\right)+\pi, \text { если } x>0
\end{array}\right.
$$

Then one should determine confidence interval $\delta$ for A

$$
\delta=\frac{\sqrt{2 x_{p}^{2} \sum_{i-1}^{m}\left[U_{i}\left(t_{i}\right)-U_{i}\right]^{2}}}{m} \text {. }
$$

$\chi_{\mathbf{p}}^{\mathbf{Z}}$ - quantile, $\chi$ - distribution corresponding to probability $\mathrm{P}$.

The authors apply the following rule: if $\delta<\mathrm{A}$, the interval exists; if $\delta>\mathrm{A}$, the interval does not exist.

Calculations in Mathcad gave the following values: $x=6$, $\mathrm{y}=28, \mathrm{~h}=138, \mathrm{p}=0.97, \mathrm{~A}=28.46, \varphi=5.4, \delta=26.97$. As can be seen, $\delta<\mathrm{A}$, which speaks for the existence of maintenance interval.

As a result, there is a mathematical model for predicting BelAZ-7540 failures:

$$
\mathrm{U}(\mathrm{t})=28,46 \cos (0,51 \mathrm{t}-\varphi)+138+0,97 \mathrm{t}
$$

Based on the data obtained, the authors create a cosine curve describing data changes (Fig. 7).

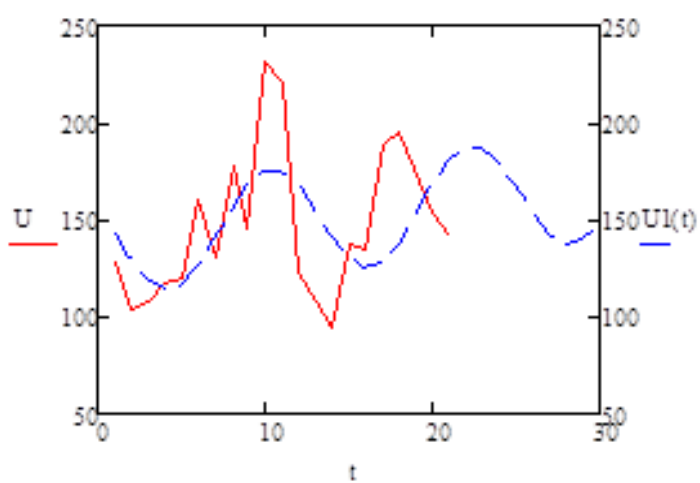

Fig. 7. Chronogram of failures and cosine: $\mathrm{U}$ - physical failures, U1(t) (Cosine) predicted failures, $\mathrm{t}-$ Months

The predictions can be inaccurate as they are based on the data about past behavior of the object. So, prediction accuracy requires assessment. Let us determine a mean absolute percent error which is a mean of absolute prediction errors expressed as a percentage to actual values:

$\mathbf{U}_{\mathbf{i} \text { - actual values of failures, }} \mathbf{U}\left(\mathbf{t}_{\mathbf{i}}\right)$ - prediction values of failures, $\mathrm{m}$ number of changes.

Calculation identified a mean absolute percent error in $3.28 \%$ which is by $10 \%$ less. It means that the prediction is highly accurate.

Thus, the cosinor-analysis identified latent failure intervals, which is indicative of their predictability. It allows us to develop a mathematical model of the number of operating time dependent failures. Along with failure prediction, the method is used for prediction accuracy assessment. It helps justify the use of preventive MR and adjust its intervals.

Engineers and researchers developed a number of methods to determine optimal MR intervals. In [9-14], methods of MR intervals are classified into analytical and graphical ones. Analysis involves calculation of MR intervals by admissible values of parameters (productivity, run time, number of 
cycles, etc.), admissible levels of freedom from failures (technical and economic, economic and probabilistic, imitation). The graphical method involves development of nomograms and diagrams. There are also combinations of these methods.

To determine a MR interval, the authors chose a graphical analytical method which involves development of interval scales and alternation of MR services. Operating time is used as a measurement unit.

According to a MR cycle determined by the plant, major repairs are carried out when operating time for the truck is $220,000 \mathrm{~km}$ or 11,000 motor hours for regions with cold climate. MR interval scale sample for BelAZ-7540 is presented in Figure 8, a.

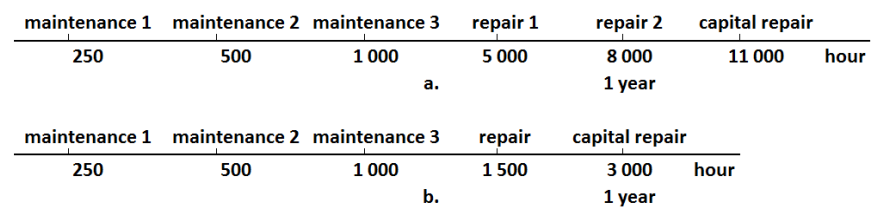

Fig. 8. MR cycle: a) preventive, b) corrective

Statistical analysis of the seven-year operation of BelAZ7540 in open-pit mines owned by JSC Almazy Anabara identified that the mean operating time of dump trucks is 2500 - 3000 hours per year, so major repair tasks are performed only every four years [15].

Mining development in the North is seasonal which causes intensive use of transport and extremely severe wear of minor components in washing seasons. Scheduled MR services cannot eliminate failures of the last season. Accumulated failures occur during intensive use of vehicles. Besides, due to intensive production, corrective MR measures might be required.

Factors, which cannot be taken into account due to the dispersion of their parameters and unpredictability of occurrences, cause failures to meet the deadline of preventive maintenance operations. They are as follows:

1. Production intensity - increase in volume of transport operations in the washing season and by the end of the season in order to meet the deadlines.

2. Complex nature of planning measures - a significant number of mining machines requires thorough planning due to the probable coincidence of maintenance periods for several machines. Workload of the maintenance personnel should be also taken into account.

3. Unexpected failures - challenges of adjusting the current schedule and specifying the volume of repair works due to different complexity and reliability of components and parts.

4. Distance and time - remoteness of mines from the company base, complex transport materials delivery scheme.

5. Quality of materials and spare parts - there are a number of companies purchasing spare parts of different quality and price.
6. The existing preventive MR system reduces lives of some components.

These factors cause waste, unsound expenses, and irrational distribution of material resources. Thus, the authors conclude that it is necessary to develop a MR system which would take into account a maximum number of various factors to reduce time and material expenditures.

The developed MR cycle structure is shown in Figure 8, b. The scheme suggests performing annual minor maintenance tasks in order to restore trucks for a new mining season. Besides, a major MR interval should be 3000 hours (annual operating time of trucks), and scheduled MR should be replaced by corrective minor MR which would ensure truck performance until scheduled maintenance.

Thus, the structure of repair works suggested by the authors is a completed repair cycle performed for one machine operation year.

To enhance MR efficiency, spare parts should be available. It restores BelAZ-7540 truck within a short period of time.

In order to compare the total labor intensity of MR services, the authors performed calculations presented in Table 1. They do not take into account the seasonal nature of MR tasks as they are performed during preparation for springsummer and autumn-winter operating periods and combined with scheduled maintenance.

\section{TABLE II. MAINTENANCE TYPES AND LABOR INTENSITY CALCULATION}

\begin{tabular}{|l|c|c|c|c|}
\hline \multirow{2}{*}{ Type of work } & \multicolumn{4}{|c|}{ MR systems } \\
\cline { 2 - 5 } & \multicolumn{2}{|c|}{ Scheduled } & \multicolumn{2}{c|}{ Corrective } \\
\cline { 2 - 5 } & $\begin{array}{c}\text { Interval / labor } \\
\text { intensity, } \\
\text { person } * \text { hour }\end{array}$ & $\begin{array}{c}\text { num } \\
\text { ber }\end{array}$ & $\begin{array}{c}\text { Interval / labor } \\
\text { intensity, } \\
\text { person } * \text { hour }\end{array}$ & $\begin{array}{c}\text { num } \\
\text { ber }\end{array}$ \\
\hline $\begin{array}{l}\text { Maintenance 1, } \\
\text { hour }\end{array}$ & $250 / 13$ & 22 & $250 / 13$ & 6 \\
\hline $\begin{array}{l}\text { Maintenance 2, } \\
\text { hour }\end{array}$ & $500 / 32$ & 11 & $500 / 32$ & 3 \\
\hline $\begin{array}{l}\text { Maintenance 3, } \\
\text { hour }\end{array}$ & $1000 / 49$ & 8 & $1000 / 49$ & 1 \\
\hline Repair 1, hour & $5000 / 230$ & 1 & Repair \\
\hline Repair 2, hour & $8000 / 492$ & 1 & $1500 / 80)$ & 1 \\
\hline $\begin{array}{l}\text { Major repair, } \\
\text { hour }\end{array}$ & $11000 / 720$ & 1 & $3000 / 720$ & 1 \\
\hline $\begin{array}{l}\text { Total labor } \\
\text { intensity, } \\
\text { person * hour }\end{array}$ & 2472 & & \multicolumn{2}{|c}{1023} \\
\hline
\end{tabular}

Table 2 shows that the total labor intensity of the corrective MR system is lower more than twice than the one of the scheduled one.

\section{CONCLUSION}

1. Analysis of BelAZ-7540 operating efficiency for the North identified that ambient temperatures influence the number of failures: at low temperatures, the number of failures is two or three times more. 
2. The scheduled MR system cannot be applied to the rhythm of mining works as it ignores real operating conditions for BelAZ-7540.

3. The graphical and analytical method for determining MR intervals involves development of a MR cycle scale based on the real operating time of the BelAZ-75040 truck for the North.

\section{References}

[1] A.M. Ishkov, M.A. Kuzminov, G.Y. Zudov, "Theory and practice of machine reliability in the North". Yakutsk, SD RAS, 2004, 313 p.

[2] P.L. Mariev, A.A. Kuleshov, A.N. Egorov, I.V. Zyryanov, "Mining vehicles in CIS states in the XXI century". Saint Petersburg, 2006, 387 p.

[3] Z.Yang, R.X. Zhang, "Research on the Equipment Addition of Antaibao Open-Pit Mine", Advanced Materials Research, vol. 734-737, pp. 619623, 2013.

[4] X.F. Li, W.B. Ni, X.M. Wang, "Thermal Load Analysis of a Brake Disc for a 220t Mining Dump Truck", Advanced Materials Research, vol. 619, pp. 188-194, 2013.

[5] Y. Chang, H. Ren, S. Wang, "Modelling and Optimizing an Open-Pit Truck Scheduling Problem", Discrete Dynamics in Nature and Society, vol. 8, 2015. DOI: $10.1155 / 2015 / 745378$.

[6] S.G. Ercelebi, A. Bascetin, "Optimization of shovel-truck system for surface mining", Journal of South African Institute of Mining and Metallurgy, vol. 109, pp. 433-439, 2009.

[7] Yu.S. Bochkarev, M.A. Vikulov, A.M. Ishkov, I.I. Sedalishchev, "Studies on dump trucks BelAZ-7540 operating in the North", Mining Information and Analytical Bulletin, vol. 7, pp. 151-157, 2015.

[8] Yu.S. Bochkarev, A.M. Ishkov, M.A. Vikulov, "Effect of operating conditions on the performance of dump trucks BelAZ-7540 Series", Vestnik of Irkutsk State Technical University, vol. 7(102), pp. 155-163, 2015.

[9] V.S. Kvaginidze, N.A. Koretskaya, "Performance of maintenance and repair service system for large load mining trucks operating in the North", Mining Information and Analytical Bulletin, vol. 5 (12), pp. 198-217, 2011.

[10] V.A. Matyushin, A.N. Ryzhkov, A.N. Tropin, V.G. Golovanov, D.E. Kozlov, "Automation of transport maintenance and repair management", Mining equipment and Electromechanics, vol. 8, pp. 18-23, 2007.

[11] G.V. Borisov, L.N. Erofeev, "Specification of the engineering and economic method for determining the optimal vehicle maintenance interval", Works of NGTU, Ground Transport Systems, vol. 4, pp. 3743, 2013.

[12] A.N. Makarova, "Specification of the engineering and economic method for determining the optimal vehicle maintenance interval", Scientific Engineering Bulletin, vol. 1, pp. 117-120, 2014.

[13] V.V. Lyandenburskiy, A.V. Grachev, L.A. Rybakova, "Morphological analysis of methods for determining vehicle maintenance interval", Internet Journal Naukovedenie, , vol. 3(22) 2014.

[14] Y. Cheng, "Predictive Analysis on Maintenance of Mining Dump Truck”, Applied Mechanics and Materialsvol. 340, pp. 848-851, 2013,.

[15] Yu.S. Bochkarev, M.A. Vikulov, G.P. Dovidenko, A.M. Ishkov, I.I. Sedalishchev, "Analysis of the performance of trucks BelAZ 7540 Series (case study of JSC Almazy Anabara)", Mining Information and Analytical Bulletin, vol. 9, pp. 394-397, 2014. 